\title{
Geotechnical justification and monitoring of subterranean parking construction in Khabarovsk City
}

\author{
Sergey Kudryavtsev ${ }^{1 *}$, Alexey Kazharsky $^{1}$, Arkades Yedigaryan ${ }^{1}$, Elena Goncharova ${ }^{1}$, \\ Leonid Yedigaryan ${ }^{1}$, Semen Bugunov ${ }^{1}$, and Evgeniya Pogulyaeva ${ }^{1}$ \\ ${ }^{1}$ Far Eastern State Transport University, Serysheva, 47, Khabarovsk, 680021, Russia
}

\begin{abstract}
The paper covers some results of the geotechnical justification and monitoring of a two-level subterranean automobile parking in the soil conditions of the Khabarovsk City. The construction project is modelled as far as the earth excavation and measuring the horizontal deformations of the pile shoring. The results of a geotechnical monitoring beyond the retaining wall and buildings of the surrounding development are offered. On the basis of the results some preventive measures necessary in the construction process are taken including reinforcement designs of the retaining wall and the residential unit subfoundations.
\end{abstract}

\section{Engineering and geological conditions of the construction}

As far as the site geomorphology, it is located within the gently rugged terrain of the Khabarovsk heights, on the north-west slope of one of them. The natural terrain is represented by a low gradient slope cut by a considerable gulley from north-west to south-west. Due to its development the gulley's area is filled and concealed. The surface marks of the site under examination accounting the man-made changes are within $6 \mathrm{~m}$.

The following types of soils are represented in the engineering and geological surveys: techno genic deposits -filled soil (tQIV); diluvia quaternary deposits (dQ); PaleogeneNeogene terrigenous deposits $(\mathrm{P}-\mathrm{N})$; Permian rocky ground $(\mathrm{P})$.

The filled soils of thickness from $0.6 \mathrm{~m}$ to $1.6 \mathrm{~m}$ are pervasive from the site surface.

The deluvial deposits are developed under the filled soils and represented by clay and sandy clay of semi-hard and hard, rarely low-plastic consistency with the granitic subsoil and crushed rock of $10 \%$ to $30 \%$. The thickness of the deluvial deposits varies within 2.5 to 8.8 $\mathrm{m}$. The Paleogene-Neogenedeposits are exposed at the depth of $3.8-8.8 \mathrm{~m}$ and are represented by mottled clay, sandy clay, hard andsemi-hard, with the granitic subsoil and the crushed rock up to $30 \%$, medium fine gravel, cobble, with loamy and sandy loamy fill of up to $20-30 \%$.

The zone of rock fracture is represented by a broken-down formation of the coal slate, sandstone of very low-strength and low-strength, dark-grey, brown, weathered and slightly

\footnotetext{
${ }^{*}$ Corresponding author: olgakudr56@mail.ru
} 
weathered state. They are exposed at the depth of 14.6-19,3 $\mathrm{m}$ (absolute mark is 31.8-34.9 $\mathrm{m})$. The thickness of cherts of low strength is $0.5-4.7 \mathrm{~m}$.

Rocky soils of medium strength, fractured, are located from the depth of 17.0-23.0 m. The rocky soils (medium strength) thickness is $1.0-11.0 \mathrm{~m}$.

The site hydrology conditions are characterized by the development of the following types of underground waters: aquifer (temporary perched ground water) in the deluvial clay soils at the depth of 2.5- $6.0 \mathrm{~m}$; underground reservoir of the terrigenous deposits which is tapped in the the granitic subsoil and the crushed rock at the depth of 11.7-17.3 m.

The water discharge is carried out in pits during their excavation while the well-point relaxation of excavation and slope protections are necessary.

\section{Design-basis justification of changes in stress and strain state of foundation in excavation context}

Traditionally the design of excavation shoring is done with analytical solutions based on the Coulomb's wedge theory. In the case under consideration it is necessary to account a possibility ofpartial realization of active and passive pressure. Thus, the design requires the models accounting a different soil behaviour at loading and unloading stages. The second important requirement to the model work behaviour is the correct description of the distortions because it is evident that in the describing case the shearing deformations prevail over the seal distortions. The soil distortion behaviour can be described in the most correct way by the viscous-elastic-plastic model contained in the software program FEM models developed by PI Georeconstruktsya, Co. The model allows both to analyse theexpected values of finite structural deformations and to assessthe development of deformations in time. The main parameters of the model can be obtained through the standard triaxle and compression tests. As the experiment modelling shows, the model allows to describe the soil behaviour quite adequately in these types of tests.

According to the design statement, a substructure of $7.0 \mathrm{~m}$ in depth is supposed to be built, and it is necessary to assess the shoring depth and stresses first, then carry out the analytical calculations of shoring in the substructure area. So, the weight of the existed building is defined according to the following parameters: $5 \mathrm{kN}$ of an average building weight of $1 \mathrm{sq}$. $\mathrm{m}$ by 10 floors of the building $3 \mathrm{~m}$ high each, that is $5 \times 10 \times 3=150 \mathrm{kPa}$.

Evenly distributed loads of $20 \mathrm{kPa}$ are applied from the retaining wall to the building (possible construction material storage, construction machines passage).

The designed depth of the retaining wall is $10.12 \mathrm{~m}$, while the required one with the coefficient 1.1 equals $(10.12-7.0) \times 1.1+7.0=10.43(\mathrm{~m})$. So, the analytical calculations show the excavation wall of a required depth is $10.43 \mathrm{~m}$ from the surface. The ultimate moments in shoring achieve $240 \mathrm{kN} / \mathrm{m}$. The shift of the wall top is about $3.9 \mathrm{~cm}$.

The calculation numerical modeling of the pile shore structure is carried out with the software Midas GTS NX. The designs are given in Fig. 1 
Fig. 1. Design scheme
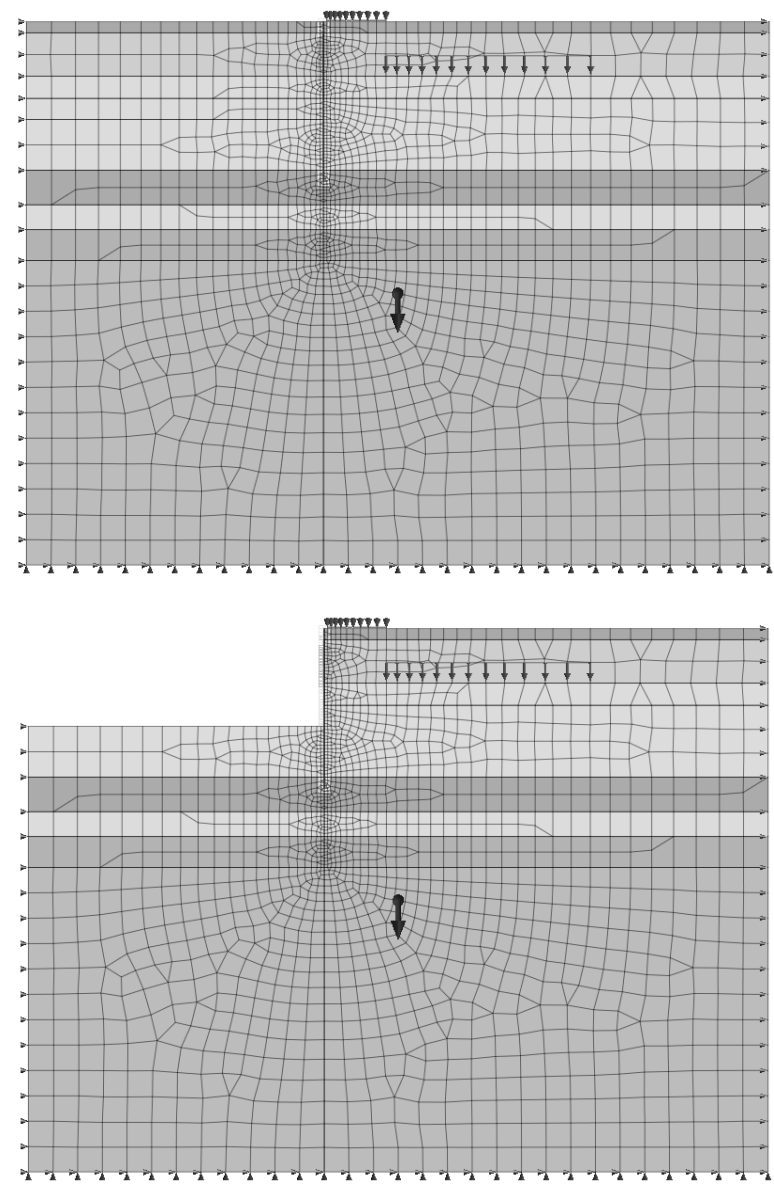

Fig. 2. Design scheme with earth excavation

As the report on engineering and geological survey does not contain data on the laboratory soil compression tests, the more complicated soil models are not used in calculations.

The calculations are done in steps:stress-strain behavior and the following each other excavation stage are taken into account. Fig. 3 and 4 show the epures of horizontal displacement and bending moments correspondingly.

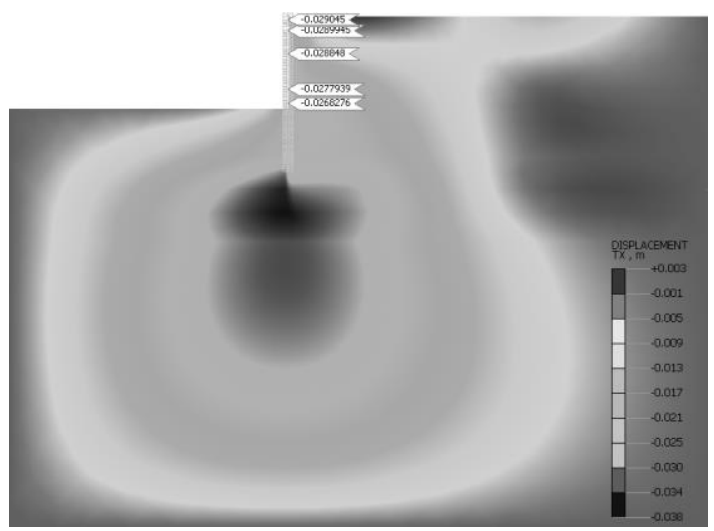

Fig. 3. Epures of horizontal displacement 

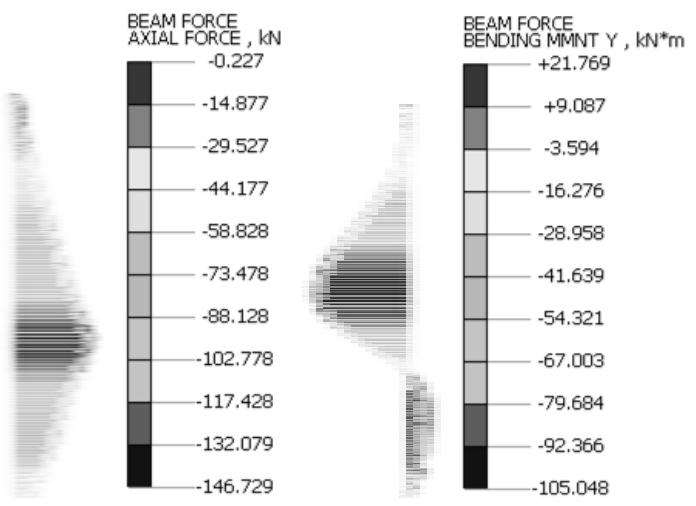

Fig. 4. Epures of axial forces and bending moments in retaining wall

As a result of the numerical modelling the maximum displacement of the wall top is 2.9 $\mathrm{cm}$ which is close to the analytical calculation. The axial force is $146 \mathrm{kN}$, while the ultimate bending moment is $105 \mathrm{kN} / \mathrm{m}$

\section{Visual and geodetic observations ofsurrounding development buildings and shoring of excavation}

The first visual survey with photo registration of defects takes place before theconstruction of the shoring of excavation starts. The aim of this work is to determine real technical conditions of the basic bearing structures (walls, slabs, staircases and the roof), civil structures and buildings in a 30-meter zone of the subterranean parking construction site.

The results of the surrounding development buildings and structures confirms their sustainable technical conditions, that means the examined building structures are in good operating conditions. The erected structures of the surrounding development buildings are done according to the project. Thus, Sad u, the admissible limit value of an additional deformation (settlement, relative differential settlement, building tilt) of the project remaining structures under reconstruction or of the adjacent development should not exceed $6 \mathrm{~cm}$. The geodetic observations are carried out with the digital level SOKKIA SDL-30 №8296using a digital fiberglass survey rod. The scheme of the settlement points for the surrounding development buildings and the horizontal points for the retaining wall is given in Fig. 5.

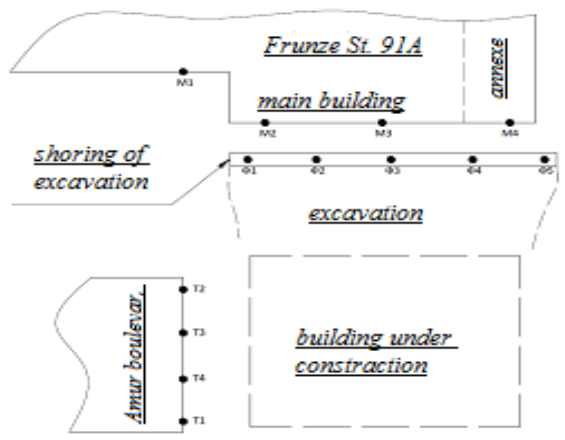

Fig. 5. Points placement scheme 
The points settlement diagrams for the residential building at the beginning of observations are shown Fig. 6.

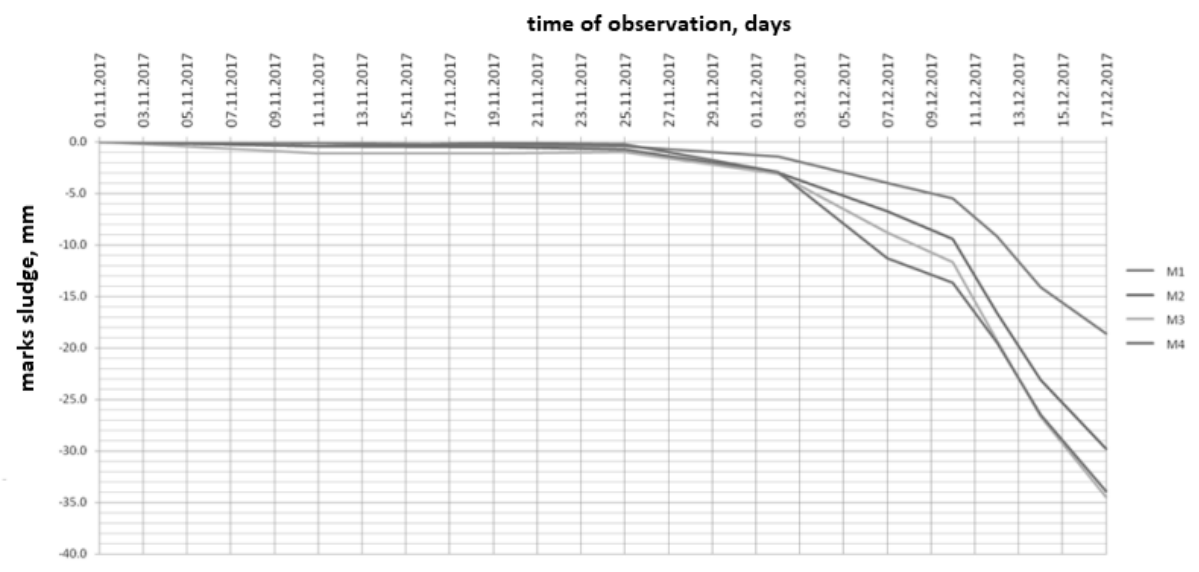

Fig. 6. Points settlement diagrams for the residential building

The maximum horizontal shift of the retaining wall in December is $14 \mathrm{~mm}$. The deformation analysis of the results in December confirms considerable deformations of 40 $\mathrm{mm}$ in the residential building. The reason of the significant deformation increment is an emergency situation with the building water supply system on the side of excavation that results in a wash-out of the sand backfill material along the wall. A large amount of water fills the excavation and leads to a degradation of physical and mechanical characteristics of the strip foundation bases of the subterranean parking.

A considerable growth ofthe retaining wall deformations is registered during the observations of deformations in the building and in the retaining wall. Some research of the subterranean parking foundation soils is required to update itsthe physical and mechanical characteristics. The geotechnical laboratory of the Far Eastern State Transport Universityfinds out that the foundation soils after a saturation turn to a frozen state and then, after thawing, to a high plasticity one. Such a soil cannot be used as the foundation but needs some preventive measures for its improvement.

\section{Design-basis justification of foundation stress-strain behavior for changed soil characteristics of excavation}

In connection with the negative factors an additional prediction calculation of the deformation development is carried out. The new situation requires some urgent measures on the shoring reinforcement. The calculation is done to change the saturated foundation for a crushed stone pad of $1.5 \mathrm{~m}$ thickness and to change the strip foundation to a mat foundation. The foundation pressure of the 10 -storey building is accepted as $200 \mathrm{kPa}$. The calculation of the retaining wall is done accounting a sand backfill for the washed out soil. Fig 7 shows a cross-section picturing a complexdesignfor the residential house, the retaining wall and the subterranean parking structure. 


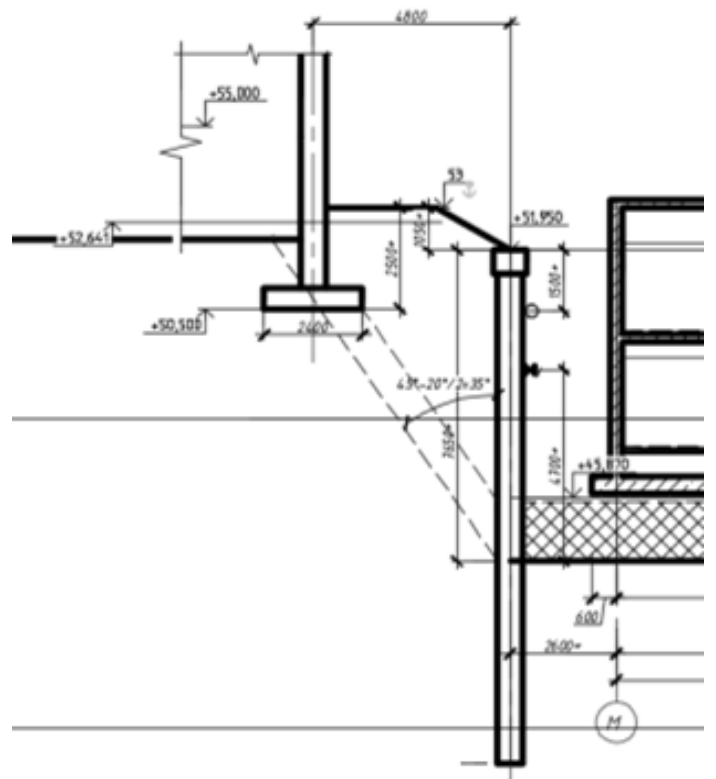

Fig. 7. Cross-section of complex designfor residential house, retaining wall and subterranean parking structure

A segment of the design model is given in Fig. 8.

a)

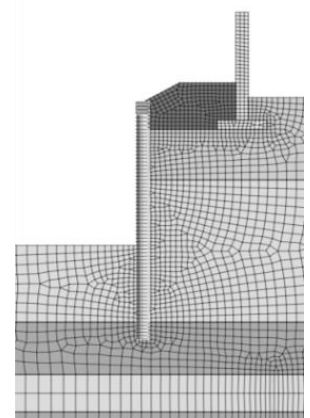

б)

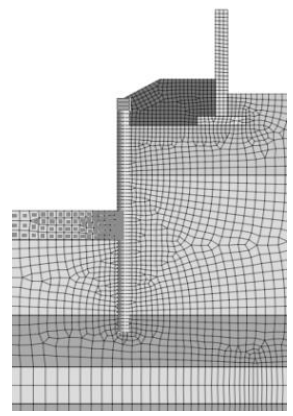

Fig. 8. Design model segment: a) w/o reinforcement; b) crushed stone pad of $1.5 \mathrm{~m}$ thick

Fig. 9 shows the horizontal shifts after the technogenic accident in both the bored pile shoring design and in thereinforcement design with the mat foundation and the crushed stone pad of $1.5 \mathrm{~m}$

a)

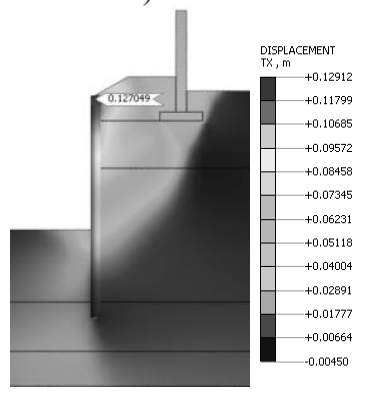

б)

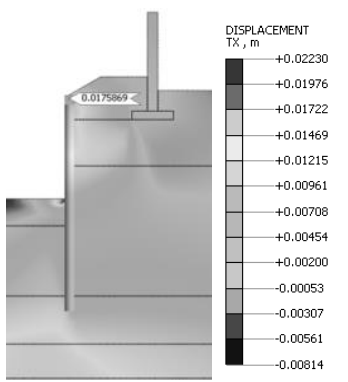

Fig. 9. Horizontal shifts in retaining wall: a) w/o reinforcement; b) crushed stone pad of $1.5 \mathrm{~m}$ thick 
The geotechnical calculations find out the following:

1) in the bored pile shoring design,the horizontal shifts at the retaining wall top are at least $12.7 \mathrm{~cm}$ (not taking into account possible consequences of the foundation soil degradation);

2) in thereinforcement design with the mat foundation and the crushed stone pad of $1.5 \mathrm{mthe}$ horizontal shifts are $1.7 \mathrm{~cm}$

It is necessary to note that the soil wash-out removes the compression pressure, and itresults in deformations in the form of foundation uplift to the side and upwards to the residential building. The pile shoring keeps the soil and foundation of the residential house from considerable deformations. The settlement of the points from their initial position is registered from $3.3 \mathrm{~cm}$ to $5.7 \mathrm{~cm}$ in the residential house for the observation period (from the accident to theinstallation of the mat foundation and the crushed stone pad).

Fig. 10 shows the diagram of the points settlement in the residential house for the whole observation period.

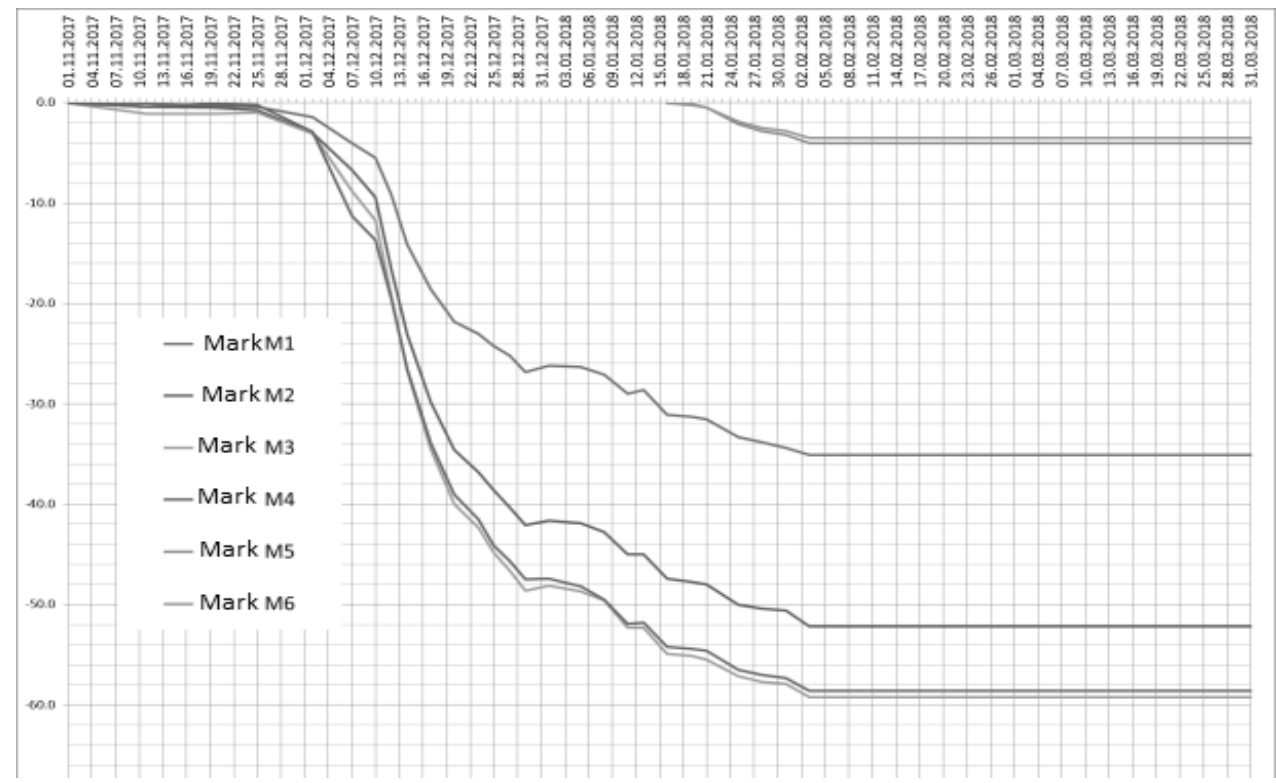

Fig. 10. Diagram of point settlement in time, $\mathrm{mm}$

Before carrying out the offered reinforcement measures some deformation preventive measures are to be done:

1) the residential building subfoundation should be reinforced with the cement and sand grout specially developed for this purpose. The subfoundation cementing is carried out to exclude subsidental deformations, recover the continuity and improve the soil strengthening characteristics.

Fig. 11 shows the arrangement of grout holes in the residential house basement. 


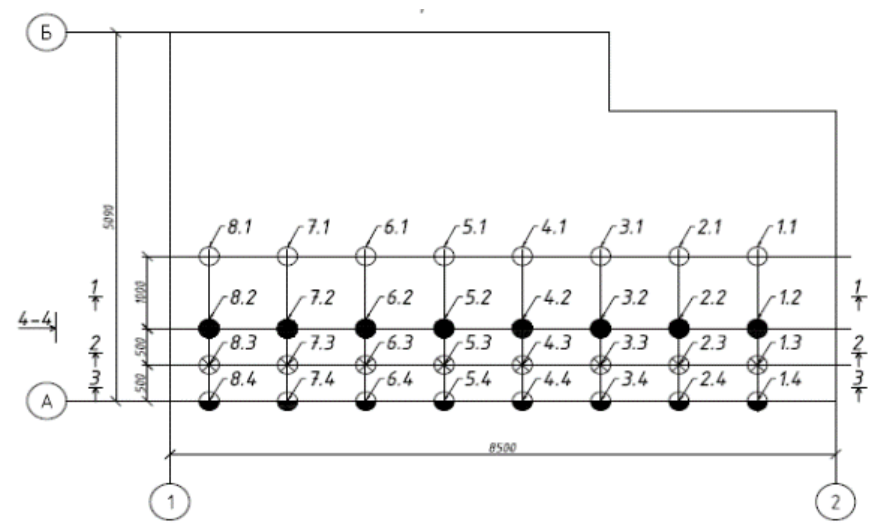

Fig. 11. Diagram of grout holesarrangementin the residential house basement

Fig. 12 shows the cementing well columns in the foundation soils of the residential house.

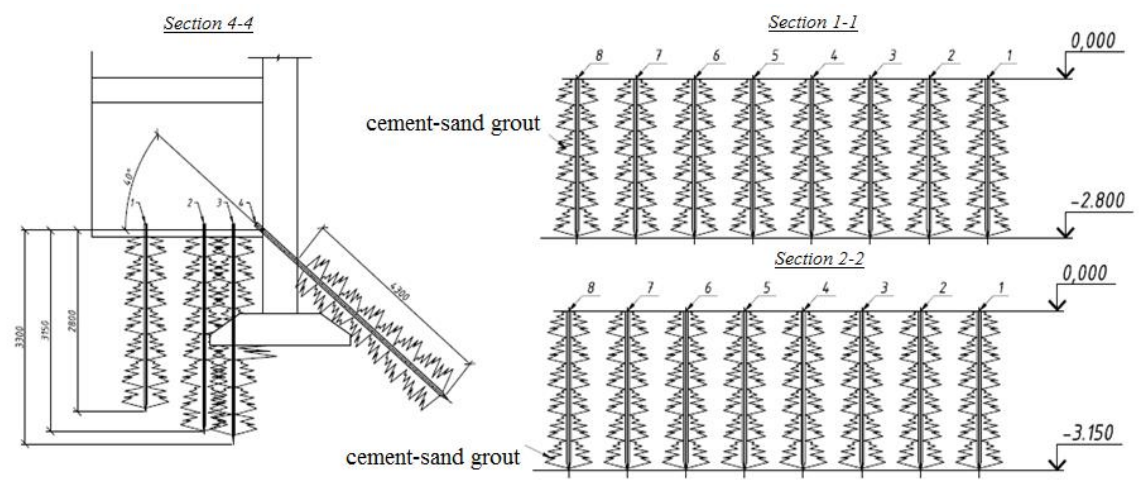

Fig. 12. Cementing well columns in residential house foundation soils

Over 110 running meters of wells are bored and grout-injected that considerably lessens the rate of deformations in the residential house.

2) The pile shoring is reasonable to be braced by pipes of no less than $500 \mathrm{~mm}$ in diameter in the flooring between first and second floors of the building under construction.

To develop a bracing design of the retaining wall it is necessary to calculate stress and strain behavior accounting the changed soil characteristics, increasing horizontal deflection of the shoring top and maximum bending moments. According to the calculationresults the type and the size of the bracing structure for the retaining wall is selected. Fig. 13 shows the excavation bracing system to reduce deformations to the permissible values after the technogenic water impact on the foundation soils of the subterranean parking. 


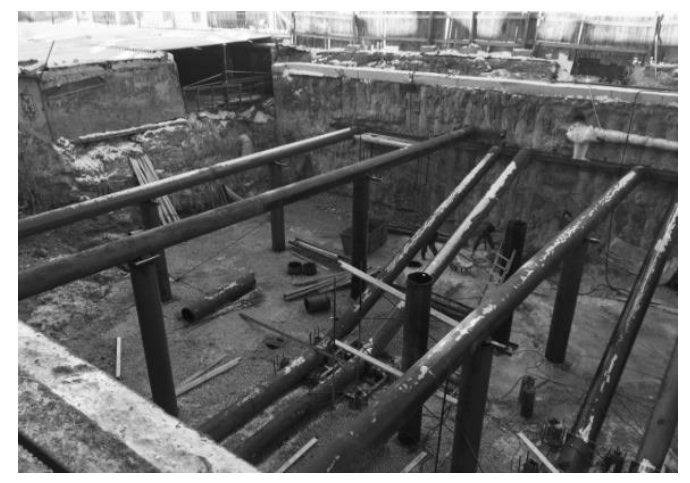

Fig. 13. Retaining wall bracing design

\section{Conclusions}

The results of scientific justification and monitoring of the subterranean two-level parking in the soil conditions of the Khabarovsk City are the following:

1) The parking construction project is modelled in the process of earth excavation, and the horizontal deformation values are determined in the pile shoring structure.As a result of the numerical modelling the maximum deflection of the wall top is $2.9 \mathrm{~cm}$ which is close to the analytical calculation. The axial force is $146 \mathrm{kN}$, while the maximum bending moment is $105 \mathrm{kN} / \mathrm{m}$.

2) The geotechnical monitoring results of the degraded soil characteristics are given after the technogenic accident beyond the retaining wall and in the surrounding development area. In the bored pile shoring design, the horizontal deflection of the retaining wall top is $12.7 \mathrm{~cm}$ not taking into account possible consequences of the foundation soil degradation.

3) On the basis of the calculations and monitoring some deformation preventive measures during the construction are done to decrease deformationsand stabilize them.

4) The subfoundation of the residential house is reinforced with the cement and sand grout specially developed for this purpose.

3) The pile shoring is braced cut with metal pipes of $500 \mathrm{~m}$ min the area between first and second floors of the building constructed in front of the excavation.

4) In the reinforcement design of the subterranean parking with the mat foundation and the crushed stone pad of $1.5 \mathrm{~m}$, the horizontal deflection is $1.7 \mathrm{~cm}$

5) The taken reinforcement measures stabilize deformations of the existed building and the retaining wall within the permissible values. They allow to carry out all the construction works on the subterranean parking on time.

\section{References}

1. S.A. Kudryavtsev, U.B. Berestyanyy, T.U. Valtseva, et.al. International workshop on scrap tire derived geomaterials Opportunities and challenges Yokosuka, Japan. March 23-24, 171-178 (2007)

2. S.A. Kudryavtsev, U.B. Berestyanyy, T.U. Valtseva, et.al. 1st International conference on new developments in geoenvironmental and geotechnical engineering. November 911, University of Incheon. Korea. 423-427 (2006)

3. S.A. Kudryavtsev, T.U. Valtseva, et.al. 9th International Conference on Permafrost (NICOP) and the field trip followed at the University of Alaska Fairbanks in Fairbanks, Alaska. June 29-July 3, USA, 323-324 (2008) 
4. S.A. Kudryavtsev, et.al. MATEC Web of Conferences, 106 (2016)

5. S.A. Kudryavtsev, Kazharsky A.V., et.al. Embankment on permafrost Eastern polygon of Baikal-Amur Mainline. International Scientific Conference on Transportation Geotechnics and Geoecology, Saint Petersburg, May 17-19, 2017. Russia. V.189, P. 774-782.

6. S.A. Kudryavtsev, Kazharsky A V et.al. Procedia Engineering, 165, 1080-1086 (2016)

7. S.A. Kudryavtsev, et.al. Procedia Engineering, 165 , 1858-1865 (2016)

8. S.A. Kudryavtsev, et.al. MATEC Web of Conferences, 73, 05002 (2016)

9. S.A. Kudryavtsev, et.al. MATEC Web of Conferences 7305007 (2016)

10. S.A. Kudryavtsev, Soil Mechanics and Foundation Engineering, 45, 177-184 (2004)

11. I.A. Korotchenko, E.N. Ivanov, S.S. Manovitsky, V.A. Borisova, et.al.Magazine of Civil Engineering 69, 56-63 (2017), doi:10.18720/MCE.69.5

12. A.V. Bushmanova, N.V. Videnkov, K.V. Semenov, Y.G. Barabanshchikov, et.al. Magazine of Civil Engineering 71, 51-60 (2017), doi:10.18720/MCE.71.6

13. E.A. Statsenko, A.F. Ostrovaia, T.A. Musorina, M.I. Kukolev, M.R. Petritchenko, Magazine of Civil Engineering 68, 86-91 (2016), doi:10.5862/MCE.68.9

14. T. Musorina, A. Katcay, A. Selezneva, V. Kamskov, E3S Web of Conferences 33, 02048 (2018), doi:10.1051/e3sconf/20183302048 